\title{
As Artes Psicofísicas na Pedagogia do Antigo Oriente
}

\author{
Lais Mourão Sá
}

Universidade de Brasília (UnB)

\begin{abstract}
Assim como o lago é inesgotável em sua profundidade, o sábio é inesgotável em sua disposição de instruir os homens. Assim como a terra é ilimitadamente vasta, sustentando e protegendo todas as criaturas, assim também o sábio sustenta e protege todos os homens, sem impor limites, nem excluir qualquer parte da humanidade.
\end{abstract}

1 Ching - Hexagrama 19

Esta é uma abordagem psicoantropológica sobre os padrões pedagógicos gerados no contexto cultural do oriente antigo, com base na comparação intercultural e na teoria junguiana da cultura. O objetivo é criar uma referência teórica para a compreensão e a interpretação das concepções pedagógicas ancestrais da humanidade. Supõe-se também que esta base etnográfica possa ser útil à pesquisa de metodologias para a Educação Ambiental e a Ecologia Humana. No texto são abordadas as categorias prático-teóricas que fundamentam a filosofia da educação nesses antigos modelos culturais, tais como: o conceito de tradição, a noção de filosofia prática, de alquimia interior, a experiência estética, a abordagem ética da ecologia e a pedagogia das artes marciais da escola interna. As conclusões remetem a um passo subseqüente, apontando as mediações necessárias para que esses modelos possam contribuir para 
a construção de pedagogias da mudança cultural, neste momento crítico da sociedade contemporanea. Tal empreendimento é parte de um projeto de pesquisa-ação, onde se testa a eficácia dos princípios pedagógicos estudados, ao mesmo tempo em que se desenvolvem processos formativos das pessoas envolvidas na experiência. Desta forma, pretende-se promover uma reflexão prática sobre ecologia humana e mudança cultural.

Introdução

Este texto sintetiza reflexões preliminares resultantes da execução de um projeto de pesquisa-ação proposto em nível de pós-doutorado, na área da Psicoantropologia Aplicada à Educação, e que visa à experimentação e à interpretação de modelos e práticas pedagógicas alternativas para a Educação Ambiental e a Ecologia Humana, tendo como instrumentos a comparação intercultural e a teoria junguiana da cultura.

As idéias aqui expostas resultam de uma prática de pesquisa-formação desenvolvida pela autora em duas frentes de atuação: como praticante de artes psicofisicas orientais (yoga, tai-chi-chuan, chi-kun, ami-jitsu) e como instrutora de tai-chi-chuan junto a grupos comunitários, há oito anos; e como coordenadora do Programa de Extensão Ambiental e Ecologia Humana do Decanato de Extensão da UnB, articulando ensino de graduação e pósgraduação, pesquisa e extensão comunitária, há três anos.

O principal objetivo desse projeto de pesquisa é testar a eficacia de modelos pedagógicos que permitam uma percepção totalizante dos fenômenos humanos, integrando os níveis psíquico e cultural, pessoal e coletivo, o homem, a mulher e a natureza. No caso das artes psicofisicas do antigo oriente, busca-se avaliar sua eficacia transformadora sobre os hábitos pessoais e culturais, as percepções de mundo, os pressupostos éticos e a consciência pedagógica de pessoas e grupos, à medida que são 
aplicados junto a grupos universitários de alunos, e junto a grupos comunitários em escolas (professores, alunos e pais) e instituições locais.

$\mathrm{O}$ texto a seguir empreende uma abordagem psicoantropológica dos padrões pedagógicos gerados no contexto cultural do oriente antigo, visando instrumentalizar sua compreensão e interpretação para uma posterior discussão sobre sua eficacia nas metodologias de Educação Ambiental e Ecologia Humana.

Ao falarmos de Educação Oriental, estamos considerando os sistemas filosóficos e psicopedagógicos do hinduísmo, do budismo e do taoismo, avaliados comparativamente em seus princípios básicos, e aproximados a partir da identificação de pontos comuns, os quais permitem identificar um padrão de "educação oriental". Da mesma forma, quanto à Educação Ocidental, estamos considerando os princípios pedagógicos derivados da filosofia da educação burguesa, que se consolidou no século XIX. Entre ambas, consideramos também o caso sul generis da pedagogia da Paidéia grega que, embora seja tida como origem histórica da cultura ocidental, apresenta descontinuidades marcantes em relação ao modelo que prevaleceu posteriormente no Ocidente, fruto das influências romanas e cristãs. Neste texto, vamos enfocar especificamente considerações sobre os padrões gerais da educação oriental e grega antigas, contextos culturais que foram contemporâneos, nos séculos anteriores à emergência da cultura romano-cristã, e tentaremos delimitar um quadro sintético de seus princípios e valores comuns, sempre tendo em mente a avaliação comparativa em relação ao modelo ocidental.

Uma forma bem genérica de se entender essa diferença é dizer que enquanto a educação ocidental se preocupa com a instrução, no sentido de transmissão de informações, os padrões orientais preocupam-se com a descoberta pessoal das verdades através da experiência direta, gerando um conhecimento experimental e visando à educação integral e à auto-realização da pessoa, com base em padrões ancestrais, codificados no arquétipo do mestre. A primeira é um sistema educacional de massas, enquanto, no outro caso, há uma relação pedagógica única e pessoal. E claro que, mesmo na 
historia oriental, vamos encontrar também o modelo que aqui chamamos de "ocidental", já que essas duas tendências constituem uma polaridade onde as diferenças se complementam. Basta ver o exemplo da antiga educação pública chinesa de inspiração confuciana, voltada para a formação do cidadão, que foi um sistema de ensino montado em grande escala, visando à seleção dos ocupantes dos cargos públicos, desde o âmbito local das aldeias até a administração central do Império. Porém, interessa-nos ressaltar aqui a polaridade Oriente $\mathrm{x}$ Ocidente, no sentido de recuperar para nossa reflexão politico-filosofica sobre a educação aqueles aspectos que possam contribuir para a criação de formas alternativas, necessidade atual urgente. Vejamos, então, alguns pontos básicos.

\section{$O$ conceito de tradição}

Um primeiro aspecto é a unicidade que caracteriza a cosmovisão oriental antiga. Para nós ocidentais, habituados às divisões disciplinares do pensamento científico, parece complicado ter num mesmo discurso uma síntese filosófica, científica, mitológica, psicológica, religiosa, ética e estética do mundo. Porém, isso se deve ao fato de que essas cosmovisões estão preocupadas com a unicidade cósmica, integrando o homem, a natureza e o social. Além disso, esses sistemas de valores e idéias se encontram culturalmente ancorados numa tradição ancestral, que garante a validação de suas verdades em nível social e a reprodução das práticas que as atualizam, no presente de cada pessoa iniciada. Quando essa relação é culturalmente saudável, o retorno às origens atua como impulso à transformação, sendo fonte inspiradora das renovações necessárias no presente histórico. Uma tal noção de tradição está bem distante da concepção ocidental, na qual o saber antigo fica cristalizado como dogma, preservado como peça de museu, desprezado ou venerado como algo já sem vida. Vemos, assim, que o papel da tradição na educação oriental é o de permitir o eterno retorno às matrizes forjadas na temporalidade ancestral.

Para exemplificar essa noção de tradição, podemos tomar o conceito de Do do Zen-Budismo, que indica a idéia de um "caminho" a ser percorrido 
pelo educando, na aquisição dos padrões ancestrais transmitidos. Tendo como referência a cultura japonesa antiga, Hammitzsche comenta que:

Desde a remota Antigüidade, a educação e a cultura já exigiam o percorrer de algum Caminho, e quem o trilha torna-se um homem desse Caminho (...)• A princípio, o Caminho nada mais era do que um aperfeiçoamento artístico a ser adquirido através de dedicada prática, realizada sob a direção de um Mestre. Houve, porém, uma transformação na época medieval, que resultou numa importante evolução. A partir de então, o homem não procura apenas determinada perícia no Caminho, porém nele também encontra agora um conjunto de princípios, verdades e ensinamentos que podem proporcionar algo ao não-especialista, ao leigo. O Caminho tornou-se uma ferramenta de instrução para os homens em geral. Dado representar uma tradição, o Caminho percorre várias gerações e será transmitido às descendências futuras, cristalizando a soma de experiências isoladas que se deram na própria prática e que, portanto, são de permanente importância para o posterior exercício do Caminho cm questão (Hammilszsche, 1991, p.7-8).

Como a tradição é algo vivo, ela deve ser experimentada em cada pessoa e cada geração como apropriação criativa:

(...) não são apenas os aspectos já maduros de um Caminho os transmitidos, pois a tradição também inclui o que ainda está imaturo, os elementos ainda em crescimento. Aí está, precisamente, o que é importante para um completo desenvolvimento do Caminho em questão, pois é parte integrante do Caminho como um todo e só poderá ser atingido por um discípulo ou aluno quando ele já conhece os degraus que levam a essa plenitude (Idem, p.8).

Para que esses elementos possam materializar-se no presente, é necessário, portanto, o esforço criativo de cada pessoa, como aprendiz iniciado por um mestre, e de cada geração, no trabalho coletivo da reprodução e recriação cultural.

As matrizes ancestrais, gravadas no exemplo vivo dos mestres, no som dos mantras, nos livros sagrados, nos cantos, nos ditos e nas práticas médico-religiosas populares são a garantia de que o mundo não se partirá 
em mil pedaços, mas permanecerá sustentando a infinita tecelagem da criação cultural pela consciência pessoal e coletiva.

Tendo em mente essa primeira aproximação, vamos enfocar, em seguida, as áreas de conhecimento envolvidas na transdisciplinaridade que é própria das cosmovisões orientais.

\section{Filosofía prática: base das antigas ciências do homem}

Enquanto sistemas filosóficos, as concepções orientais consideradas aqui são monistas ou não-dualistas. Elas partem da percepção da unidiversidade do Universo, ou seja, da concepção de que o mundo que percebemos é a manifestação de uma dimensão transcendente de realidade, não-manifesta, a qual, ao se manifestar, engendra o vir-a-ser ou o acontecer cósmico. Dentro da totalidade cósmica, o homem e a natureza são vistos numa relação de parte-todo, envolvidos numa mesma trama de circulação de energias, que se equilibram em redes integrativas, compondo um todo constantemente mutável (relações holísticas, ou holográficas, poderíamos dizer). A totalidade é um ser vivo que respira pela rede de vibrações energéticas entre os holons, assim como o homem respira com todas as pulsações de seu corpo. Este tipo de fundamento filosófico do pensamento parece refletir um arquétipo na história da consciência humana, o qual tem recebido no pensamento ocidental o nome de Filosofia Perene:

Philosophia perennis - a expressão foi cunhada por Leibniz; mas a coisa, a metafísica, que reconhece uma Realidade Divina substancial no mundo das coisas, das vidas e das mentes; a psicologia, que encontra na alma algo semelhante à Realidade Divina, ou idêntica a ela; a ética, que coloca o termo final do homem no conhecimento do fundamento imanente e transcendente de todo ser - a coisa é imemorial e universal. Encontram-se rudimentos da filosofia perene no saber tradicional de povos primitivos em todas as regiões do mundo e, em suas formas mais plenamente desenvolvidas, em cada uma das religiões mais elevadas (Huxley, 1991, p.9).

Nesses sistemas antigos de pensamento, a filosofia é fruto do exercício de um conhecimento prático sobre o mundo natural, o qual conduz 
à percepção da qualidade viva de todos os seres e à comunhão/comunicação homem-natureza. O pensamento de Heráclito (Grécia, VII-VI aC) é um exemplo dessa concepção de natureza, ou de mundo real, nomeado como Physis, a energia da natureza que "ama esconder-se", e só se manifesta momentaneamente, fazendo e desfazendo suas formas sem cessar, negandose e afirmando-se na tecelagem do mundo real. O mundo é visto aí como manifestação energética, ou seja, como tensão polarizada, unidade polêmica, harmonia de tensões, onde "o divergente consigo mesmo concorda", e onde os contrários se reúnem na realização e completude dos ciclos.

Do ponto de vista de uma compreensão antropológica da consciência humana, podemos afirmar a existência de três modalidades básicas de linguagem, que são o mitologizar, o filosofar e o pensar-fazer técnico-científico. As mais antigas linguagens que expressam a experiência coletiva da relação simbiòtica e empática com o real são os sistemas mitológicos. O mitologizar é uma função criativa da consciência, que propicia uma percepção intuitiva da unidiversidade cósmica, expressando-se em linguagem simbólica, a forma de linguagem mais apropriada à sua apreensão imediata. Em todas as culturas, o mitologizar corresponde à expressão da experiência de união entre o homem e as forças naturais, permitindo-lhe atuar intuitivamente no mundo através dessas forças, mediante modos simbólicos e ritualizados específicos de cada contexto social.

Enquanto o mitologizar é o modo típico de expressão da consciência simbolizante, o filosofar caracteriza-se pelo indagar e conceituar, e a consciência científica pela integração entre o saber e o fazer. Simbolizar, conceituar e saber-fazer são, assim, três funções da consciência humana, que se combinam culturalmente sob as mais diversas formas, viabilizando na prática os processos coletivos de construção do real cotidiano e das cosmologías. A noção de ciência e a de experimentação que a acompanha, por exemplo, apresentam quase sempre um elemento básico de relação simbiòtica e empática com o real, pelo menos nas antigas ciências da natureza, onde o homem se comunica com esta como um ser vivo, que com ele dialoga, numa linguagem cifrada, cujo código é preciso desvendar. Tal é a origem dos sistemas de oráculos, tão comuns nessas antigas tradições, que fazem com que a reflexão científica 
permaneça ligada à sua base filosófica e mitica, de forma coerente e totalizante. A Astrologia, como modalidade de conhecimento, é uma ciência desse tipo, que faz uma leitura oracular da natureza, a partir da dimensão subjetiva, segundo linguagens mitológicas e matemáticas precisas. Na tradição taoísta,

o / Ching é outro exemplo, ao se utilizar de uma concepção matemática da mutação, para efetuar uma tradução significativa dos eventos entre as dimensões natural e humana.

O que estamos chamando aqui de Filosofia Prática, portanto, são sistemas de pensamento que combinam as três funções básicas de expressão da consciência, a partir da aceitação de algumas verdades essenciais, tomadas como fundamentos de uma experiência mítico-simbólica, conceitual e técnica da relação homem-cosmos. Como veremos a seguir, as pedagogias orientais utilizam-se tanto da linguagem ritual e simbólica quanto da indagação racional e da pesquisa experimental dos fenômenos naturais, para ordenar e sistematizar um conjunto de conhecimentos a serem reproduzidos e recriados, na transmissão entre as gerações.

\section{Medicina psicorreligiosa: uma alquimia interior}

Vemos, assim, que as antigas ciências do homem que estamos examinando preocupam-se em compreender a ligação entre o ser da natureza e o ser humano. Para a percepção desta inter-relação, criaram-se conjuntos de práticas de alquimia interna e externa, as quais foram aos poucos sendo fixadas em torno de alguns sistemas específicos. O termo alquimia referese a sistemas de conhecimento e experimentação da dinâmica dos fluxos de energia que ligam homem-natureza. Vamos considerar aqui, como exemplo, os sistemas de alquimia interior fixados nas diversas modalidades do yoga indiano e nas artes marciais de escola interna.

No Ocidente, existe atualmente uma preocupação crescente, na linha da Psicologia Transpessoal, com essas técnicas de alquimia interior, as quais chegaram até nós rotuladas com o nome genérico de "Meditação" (cf. Naranjo, 1991). 
Para descrever o que há de essencial por trás dos rótulos, ou seja, o que coincide com a herança ancestral da visão oriental, podemos falar de um sistema de técnicas para a auto-observação, baseado numa concepção energética da natureza e numa fenomenologia dos estados de consciência. Enquanto percepção energética, o corpo humano é visto como um agregado de campos de força vital, os corpos energéticos que se interpenetram nos planos físico, emocional, mental e espiritual. Esses campos são utilizados como veículos de estados de consciência, passíveis de clara distinção enquanto entidades atuantes nas dimensões de real que lhes correspondem. O estado de consciência que preside o eu social, o ego como centro consciente de um conjunto de papéis e máscaras sociais, é considerado o estado mais embrutecido da consciência humana, acima apenas da animalidade sem autoconsciência. Esse ego deve ser "esvaziado", ou seja, deve ser englobado e comandado por estados de consciência superiores, capazes de obter uma clara percepção dos níveis de realidade mais sutis, imateriais e totalizantes.

O contato com esses estados mais sutis de consciência é alcançado através do exercício da meditação, que permite dissolver aos poucos a sensação de que a personalidade seja algo separado do todo. Enquanto padrão técnico especificó, a meditação é um trabalho constante de centramento, potencialização, condução e projeção de energia vital, que é transmutada e sutilizada no exercício das práticas prescritas. O principio técnico básico é a ligação mente-corpo através da respiração e de imagens mentais (ver a descrição deste aspecto no item sobre Artes Marciais), gerando relaxamento, descontração das tensões em todos os planos e a construção da noção interior de centro vazio.

Esse centro é, na verdade, um fluxo centro-vertical (que se expande num complexo sistema de caminhos verticais - os meridianos), ligando o homem às forças do céu e da terra, e contendo pontos de abertura ou "portas giratórias" (vórtices ou chacras), que captam e emanam/projetam energia vital. O trabalho da respiração visa potencializar essa força circulante no interior desses canais e centros dinâmicos. Os efeitos psíquicos e físicos de 
um tal trabalho resumem-se na integração e na harmonização dos veículos pessoais e na dissolução progressiva dos apegos físicos, emocionais, mentais e espirituais da mente. $\mathrm{O}$ objetivo final é alcançar um estado permanente e cotidiano de consciência desperta, fruto do esvaziamento, ou daquilo que os chineses chamam de wu-wei, a não-ação (ver o item sobre Estética).

O "vazio" oriental não é sinônimo do "nada" ocidental. Ele indica um estado puro da energia que permite o estar no mundo sem acumular conteúdos, sem tensões, apenas a mente aberta e centrada, capaz de expandir infinitamente a percepção. Esta noção de vazio também evoca a experiência do silêncio, como o pólo oposto que se segue à vibração sonora e que lhe confere o pleno sentido. $\mathrm{O}$ tema do esvaziamento do ego e o silêncio interior e exterior aparecem relacionados no exemplo da cerimônia do chá:

Cada Caminho japonês almeja penetrar na essência do eterno e vivenciar o Todo-Uno. Porém, essa meta só é alcançada quando o caminhante - aquele que procura - abdica de seu próprio ego e vivencia a ausência do eu e o vazio. E um silêncio tão profundo que ressoa, e este som permite a quem o escuta, uma vez alcançada sua maturidade, vivenciar repentinamente o TodoUno. E um tal silêncio reina sobre o Caminho do Chá que, em última instância, faz ver o Caminho que conduz ao próprio ser (Hanunitzsche, 1991, p. 10).

Embora tudo isso pareça dificil e inalcançável para o estado mental da consciência ocidental, a técnica da meditação é extremamente simples e natural, podendo ser praticada por qualquer pessoa que deseje treinar a mente para o autoconhecimento e a religação com a natureza. Além disso, essa técnica tem implicações éticas, sociais e políticas, ao permitir a superação dos conflitos interiores, realizando a harmonia dos opostos. Desta forma, ela propicia a integração homem-natureza-sociedade, ensinando a arte de transitar entre a separação e a união com o todo (samsara-nirvana), entre a afirmação do eu e a ressonância harmônica com o grupo, as outras pessoas e as forças vivas da natureza.

Podemos afirmar, portanto, que esses sistemas complexos de conhecimento codificaram suas noções pedagógicas básicas através de uma 
medicina psicorreligiosa cujas práticas preventivas e curativas se baseiam na suposição de que o ser humano seja um holon. Isto significa que ele é visto como um sistema aberto, um agregado de campos de força vital, cuja purificação e integração levam a um estado de equilíbrio que se chama "saúde". Este conhecimento pràtico-teorico foi construído através da experimentação realizada por todos os grandes mestres da Antigüidade, os quais organizaram, codificaram e transmitiram as técnicas de observação de si mesmo e do mundo. A experiência de ser um ente conectado à rede da energia universal foi, portanto, o fato que gerou a produção desses conhecimentos, tal como foram desenvolvidos, por exemplo, pelos sistemas ayurvédico, tibetano e taoísta, em suas respectivas tradições. Por trás das diferenças de linguagem e das formas simbólicas de mapeamento da ação, encontramos concepções básicas comuns sobre a possibilidade de uma atuação consciente nos campos de força vital, no homem e na natureza como um todo. A idéia de força vital integra também as dimensões biológica e psicológica, que a ciência ocidental separou como dois tipos distintos de fenômenos. Assim, o campo do conhecimento sobre a psique humana aparece nos sistemas orientais como um afluente de um rio principal, que é a busca da compreensão e da comunicação com o cosmo e da alquimia das energias vitais. É também impossível separar esta concepção biopsíquica das práticas rituais de caráter religioso. Sendo objeto de um conjunto de antigas ciências humanas que têm por base uma filosofia prática, os fenômenos psicofisicos só se deixam abordar através da experiência subjetiva do aprendiz. Os instrumentos de pesquisa desse campo de fenômenos foram, assim, as práticas ritualizadas que a tradição codificou como meios de comunicação do ser humano com uma natureza socializada, representada na linguagem simbólica dos sistemas religiosos e ancorada na experiência estética da união entre o humano e o divino.

Temos, assim, a questão do significado, da interpretação do mundo e da criação simbólica, que é hoje o centro do pensamento fenomenológico e hermenêutico nas ciências humanas, como uma dimensão prática de realização da consciência coletiva e pessoal, que já estava colocada nas antigas ciências do homem. A expansão da percepção e o domínio consciente da força criativa 
da natureza, que a meditação desenvolve, atuam sobre a função simbólica da consciência, como um canal de comunicação elementar entre o homem e a natureza, pois é na linguagem simbólica que se manifesta a energia criadora. Assim, a riíualização das práticas não é apenas um ornamento dispensável pelas mentes mais racionais, porém é o único instrumento eficaz, quando se trata da alquimia das energias psíquicas. Além disso, vimos que a percepção oriental do fenômeno da consciência distingue entre um nível social básico de formação da identidade, centro do ego, que usa os códigos culturais já prontos, e uma série de outros níveis de consciência correspondentes a planos energéticos mais sutis. Através destes, uma identidade totalizante, pessoal e única, quer manifestar-se como vontade consciente, capaz de atuar em ressonância com a energia criativa do Universo. Podemos notar, por exemplo, que até mesmo na noção oriental de ascese, de disciplina rígida, persistência e continuidade das práticas, existe a expectativa de que o iniciado ou educando crie sua própria verdade, pessoal e nova, a partir da esquematização sintética dos símbolos e das técnicas codificadas pela tradição, liberando forças bloqueadas e descobrindo conexões insuspeitadas.

\section{Estética}

O aspecto da criatividade levanta, assim, a estética como dimensão a ser considerada em nossa reflexão sobre as pedagogias orientais. A estética oriental não poderia deixar de estar intrinsecamente ligada à cosmovisão dominante, entendendo o ato humano de criação das formas como uma continuidade do fluxo natural das formas universais. Os seus valores de julgamento da beleza e da perfeição da obra baseiam-se nos princípios observados na manifestação da natureza. Dessa forma, o verdadeiro artista pratica uma auto-observação participante, percebendo a si mesmo enquanto fenômeno natural e domando a energia que flui por seus veículos, para que estes possam ser canais de expressão da força criativa do Universo.

Os taoístas, por exemplo, têm o conceito de wu-wei, significa a não-ação, o estado de consciência vazio e aberto, de união plena com o 
mundo, que alguns antropólogos chamaram de "participação mística primitiva" (cf. Oliveira, 1991). Em qualquer tipo e estilo de arte oriental (da ikebana às artes marciais, passando pela pintura, dança, teatro, escultura, arquitetura, música etc), as técnicas se transmitem através do cultivo pessoal de uma percepção refinada das energias que circulam entre o universo interior e o mundo externo. $\mathrm{O}$ artista traduz esse contato em formas criadas a partir da energia simbólica transmitida nas linguagens culturalmente existentes e registradas originalmente nas mitologias antigas. E no impulso do instinto de linguagem próprio dos humanos que a energia do símbolo atua, mobilizando forças psíquicas interiores, usadas pelo artista para criar sua obra. O criador busca a improvisação do gesto, que deve ser totalmente não intencional (como o estado mental do arqueiro zen), tecendo com a imaginação a trama real de sua obra, ou, como disse o poeta, "a agulha do real nas mãos da fantasia" (Gilberto Gil). O que nós chamamos de improvisação no ocidente talvez não corresponda exatamente ao wu-wei taoísta, pois não se trata de gestos ao acaso, mas de um estado de sincronização perfeita com as forças naturais conectadas pela consciência. Aqui também são utilizadas as técnicas de auto-observação básicas da meditação, como método de desenvolvimento dessa atitude interior de sutileza e suavidade, que permite esvaziar emoções e pensamentos, observar, respirar e relaxar, entrando em ressonância com os ritmos naturais.

Jung nos ensinou que é própria da natureza humana a necessidade de expressão da consciência numa linguagem, e que esta se apresenta à consciência como uma dimensão temporal e historicamente construída, nas formas codificadas em cada cultura (mito, filosofia, ciência, arte, religião). Ele mostrou também com bastante clareza a natureza energética do símbolo, seu poder de mobilizar as forças psíquicas humanas, conduzindo-as desde os níveis mais instintivos às formas mais refinadas de expressão da consciência desperta (cf. Jung, 1928-1987). E, além disso, Jung percebeu que a criação das formas simbólicas é guiada por um tipo de "consciência da espécie", que chamou de inconsciente coletivo, porque é geralmente inconsciente para o eu social, mergulhado nas imagens tradicionais de cada cultura. Essa consciência da humanidade forma-se através do registro 
cumulativo de estruturas energéticas básicas, os arquétipos, registro que ocorre no cérebro humano coletivo (transmissão hereditária). São os arquétipos que garantem a validade psíquica da tradição, e que permitem também a liberação da energia criadora que inspira o artista. Os mestres taoístas aconselham "estudar o pensamento antigo, captar sua essência e expressar o Tao por si mesmo" (cf. Normand, H., 1987). Os arquétipos, ao mesmo tempo em que são portadores da essência da tradição, apresentam o caminho da expressão criadora, enquanto energia pura que pode assumir as mais variadas formas (ver o exemplo dos arquétipos do guerreiro e do mestre, a seguir). É a energia arquetípica, contida nos símbolos mais centrais de cada cultura, que permite a renovação criativa da expressão simbólica, fazendo fluir através da consciência vazia a manifestação da arte natural.

Tomando o exemplo da estética taoísta e de sua pedagogia, vemos que a aprendizagem das habilidades estéticas é codificada através de quatro etapas, apontando-se, primeiro, o estado inferior da consciência, sem ressonância com os ritmos naturais, porém chegando-se, através da autodisciplina, a uma performance prazerosa e sem esforço. Progressivamente, os estados interiores da subjetividade vão entrando em harmonia com os efeitos exteriores da forma, alcançando-se, por fim, a perfeição do completo vazio, o estado primordial de união entre a consciência e o mundo.

A pedagogia da arte-educação não visa apenas à perfeição puramente técnica, mas sim ao

(...) desabrochar do caráter de um homem, tudo o que aproxima a essência do seu ser da sua plenitude, tudo o que forma as suas capacidades tanto manuais como espirituais, levando-o a atingir a maturidade (Hammitzsche, 1991, p.9).

O processo da criação é construído partindo-se do seu pólo oposto, que é a imitação do padrão transmitido pela linhagem ancestral (tradição), cada artista construindo a si mesmo e à sua arte a partir desses padrões. No exemplo da arte zen da cerimònia do chá, o discípulo

(...) deve ater-se à experiência de um Caminho, assim como ele lhe foi transmitido e aperfeiçoado de geração em geração, representado na forma 
de um modelo concreto, ou através do legado oral ou escrito. Nenhuma liberdade lhe é concedida. A liberdade pessoal de agir espontânea e criativamente lhe é negada, pois esta não é a verdadeira liberdade que se deve almejar. Só quando consegue subjugar seus caprichos, alcançando a disciplina de si próprio - tendo, portanto, vivenciado em sua totalidade o que recebera - poderá o discípulo reconhecer aquilo que contém um valor eterno para o seu próprio Caminho. Ele terá atingido, então, a maturidade e poderá ir ao encontro de sua própria criação que, nesse momento, surge espontânea no interior de seu ser (Ibidem).

Vemos, assim, que o método de cultivo da criatividade nas pedagogias orientais nada tem a ver com o individualismo ocidental, que valoriza os "dons inatos" de um ego isolado. A arte-educação oriental busca preservar o contato do eu pessoal com as fontes primordiais da criatividade, gravadas nos modelos ancestrais transmitidos, os quais, por sua vez, se inspiram nas forças naturais que movem o homem. São as mesmas bases que alicerçam as práticas médicas e psicorreligiosas de que falamos acima.

\section{Ética, Pedagogia e Ecologia: o exemplo grego}

Podemos aproximar-nos também das pedagogias orientais tentando compreender suas concepções éticas, sua visão sobre o que é educar e o que deve ser transmitido como valores básicos. A palavra grega ethos expressa o sentido da realização de um modelo ideal, ou divino, que se manifesta como presença consciente em cada ser, e tal é, também, o sentido básico da ética orienta] e da pedagogia que a acompanha: a auto-realização de um modo de ser ideal, sempre renovado na expressão consciente de cada pessoa.

A Ética e a Pedagogia encontram-se aí indissoluvelmente ligadas num laço comum que as articula aos princípios gerais recolhidos da observação da natureza. Tomando o exemplo da cultura grega antiga, encontramos a idéia de uma correlação básica entre as leis da natureza e as leis da comunidade humana, ou seja, as relações entre os homens, na polis, buscam reproduzir o ideal de equilíbrio, perfeição e beleza revelado pela natureza do cosmo. As virtudes prescritas são registradas cultu- 
raímente na consciência coletiva sob a forma de um ou mais arquétipos, indicando as qualidades do modelo ideal de homem superior (paideià), as quais são ensinadas no exemplo vivo dos mestres, para a educação da elite, os cidadãos da polis.

A Pedagogia tem por meta, assim, a formação dos hábitos cotidianos eficazes para desenvolver as virtudes valorizadas e cultivar atitudes correlatas. As codificações ritualizadas geram uma ética vivencial, absorvida na experiência direta e na compreensão prática. Já vimos como os procedimentos metodológicos de ritualização das práticas aparecem na pedagogia oriental para viabilizar a alquimia das energias psíquicas e a expressão da experiência estética. Encontramos, agora, o papel da ritualização enquanto modo de transmissão e aquisição das virtudes éticas que orientam as ações corretas do homem perante a natureza, os outros homens e a si mesmo, o que poderia ser dito o fundamento de uma ecologia humana, ou de uma ecoética, o conjunto de valores que orienta as relações homem-natureza-sociedade (cf Unger, 1991). A palavra grega oikos refere-se tanto ao modo humano de habitar o mundo quanto à experiência interior de união com a natureza. Nas cosmovisões orientais, essa percepção filosófica, científica e estética da unidade cósmica e da harmonia entre o homem, a natureza e a sociedade, torna-se internalizada no aqui-agora das forças vivas que unem os homens entre si e com a natureza, pois os comportamentos ritualizados atualizam constantemente a consciência de pertencimento do holon ao holos.

Esse sentido da percepção ecológica, que ainda não se tornou plenamente incorporado ao campo do pensamento científico e pedagógico atual, se constitui, no entanto, um aspecto básico das cosmovisões antigas, as quais nos transmitiram através de alguns arquétipos os princípios pedagógicos elementares de uma ecoética. Os arquétipos que transmitem o modelo ideal de homem apontam sempre para um processo de realização total da natureza própria de cada ser, no esforço de integrar suas multidimensões existenciais, para expressar sua versão pessoal do padrão cultural legitimado e reconhecido como o mais alto valor na comunidade dos iguais. Jung chamou a esse processo de individuação, tentando não só corrigir o individualismo cristão-burguês (não é um tornar-se separado dos demais), como também apontar para a 
importância da simbologia do eu (eu social, máscaras, eu superior, divindades), nesse movimento de ampliação da autoconsciência.

No caso das pedagogias orientais, os arquétipos que melhor expressam esse aspecto são os do Guerreiro-Herói-Aprendiz e o do Mestre. Os mitos dos heróis culturais, geralmente também guerreiros, veiculam modelos de conduta social valorizados e reconhecidos sob a forma de honra e respeito. Eles transmitem sempre orientações para uma atitude prática de auto-educação, mostrando o herói como eterno aprendiz, em busca da realização do modelo de perfeição. Ele deve exercitar-se numa disciplina de experimentação direta, transmutando suas energias, sutilizando essências vitais e psíquicas. As orientações técnicas para o aprendizado estão diretamente codificadas na manifestação do arquétipo do Mestre, que pode ser ou não personalizado, mas perante o qual o discípulo deve desenvolver as virtudes da devoção, da receptividade, do respeito, da confiança e da gratidão. Assim, enquanto aprendiz, o guerreiro nunca perde a referência ética a um halos social e cósmico que o determina, e com o qual ele cultiva uma relação de completa ressonância. Esta é sua grande virtude.

Quanto ao Mestre, é o espelho e a matriz da tradição, atuando simbolicamente como canal de manifestação desses valores em seu próprio ser, em sua presença autêntica, na eficacia espontânea de seu poder psíquico perante o discípulo. Ele nunca é um ser isolado, mas um elo numa cadeia de transmissão de um saber que gera um poder.

Tradição, no sentido japonês, nao é mera transmissão de algo estabelecido, acabado, criado por um Mestre. Tradição significa o ensino de um Mestre em sua totalidade e o "contínuo vivenciar" do seu legado em toda a sua plenitude (Hammitzsche, 1991, p.8).

A principal virtude do Mestre é a compaixão, que o faz assumir com o discípulo a condição de companheiro de viagem. A compaixão é fruto da experiência de ser parte de uma totalidade que engloba e determina o ser individual. Percebendo-se como sendo um elo da cadeia, o Mestre atua como tal perante o discípulo, revelando-lhe em seu ser sua forma pessoal de vivenciar o que lhe foi transmitido. 


\section{Artes marciais interiorizadas: a pedagogia do guerreiro}

A união dos arquétipos do Guerreiro e do Mestre, concebidos numa relação de reciprocidade perfeita, expressa com precisão simbólica a pedagogia das artes marciais de escola interna ou interiorizadas. Com esta denominação, referimo-nos às artes marciais que se baseiam no uso da energia vital interior para a superação dos obstáculos e consecução das metas, no caminho espiritual e social do guerreiro (como, por exemplo, o tai-chi-chuan e o wu-shu, na China, o aikido, o iai-do, o kiu-do [arco], o jo-do [bastão] e o ken-do, no Japão).

No Japão, por exemplo, a história das artes marciais registra o surgimento dessa tendência a partir do século XVI, quando,

de meio prático de combale, visando à morte, passaram a ser um treinamento educativo espiritual que enfatizava o desenvolvimento pessoal do praticante. Assim, a arte de combater com uma espada, "kenjutsu", converteu-se no "caminho da espada", o "kendo". Não tardou para outras artes marciais receberem o sufixo "do", que significa "o caminho", ou, mais precisamente, "o caminho para a iluminação, a auto-realização e entendimento" (Hyams, 1992, p. 12).

Nessas artes, encontramos como base técnica os mesmos princípios da meditação e da alquimia das energias encontrados na medicina psicorreligiosa, aplicados para a introspecção, a auto-observação e a geração contínua da energia vital utilizada na luta. Nas artes marciais taoístas, por exemplo, a sutilização da qualidade do ki (energia vital) interior dá-se através do treino da respiração pré-natal, que é uma pulsação básica do agregado corporal, independente da respiração pulmonar. Entrando em contato com essa pulsação, que tem como foco o ponto energético localizado no centro do baixo-ventre, onde o cordão umbilical ligava o feto ao corpo materno, $o$ praticante pode deixar fluir espontaneamente a respiração superficial e manter-se conectado com os ritmos profundos e sutis da natureza, esvaziando tensões fisicas, emocionais e mentais.

Assim como todas as artes e caminhos da pedagogia oriental, as escolas de artes marciais ensinam a aquisição de um modo harmonioso e natural de 
ser e estar no mundo e consigo mesmo. Enquanto modelo filosófico, ético e de ecologia humana, essa atitude é simbolizada nas artes marciais pela imagem da roda e da espiral, indicando o movimento axial que liga o homem ao cosmo, evocação psíquica do monismo filosófico e da integração holística entre a parte e o todo. No exemplo do ami-jitsu*, o princípio filosófico de que "o centro do Universo é o centro do homem" (Tibery, 1983, p.52) corresponde à percepção do fluxo da energia entre os parceiros ("a mente e as emoções não devem estar presas a nada, e sim livres para captar e sentir", p. 141) e corresponde também aos movimentos de giro em torno do próprio eixo, que permitem desviar a força do ataque e revidá-la em forma de defesa, sem esforço muscular concentrado. Passa-se, assim, de uma idéia filosófica a um princípio técnico, na medida em que todo movimento é entendido e percebido enquanto integração homem-cosmo:

Como os seres e ludo mais são partes do Universo, também eu sou parte do Universo. Quem me ataca, ataca o Universo e, em resumo, agride a si mesmo. Do mesmo modo, destruir a natureza é destruir a si próprio. $\mathrm{O}$ ami-jitsu caminha positivamente em termos de trabalho de corpo e em filosofia. Busca formar o homem integrado, harmonizado com o Universo, apto a viver no mundo material. Consciente, pois, do seu papel espiritual (Tibery, A., 1993, p.15).

Outro exemplo interessante são os ensinamentos do Caminho do Guerreiro, com base nos textos tântricos que falam do lendário reino de Shambala, e de seu significado psíquico interior (cf. Trungpa, 1991). Esses ensinamentos articulam os princípios do sagrado, da dignidade e da valentia, para descrever o espírito guerreiro, inspirado no exemplo mítico do grande rei tibetano Gesar de Ling, e na forma como este conseguiu vencer a condição rude do espírito humano através desses princípios. Para isso, o praticante deve descobrir a energia autogerável do Universo dentro de si mesmo, simbolizada na imagem do "cavalo do vento", energia interior

\footnotetext{
* Arte marcial defensiva criada em Brasília pelo mestre Antonio Tibery Costa, a partir de sua formação em jiujitsu, judo, aikido, iai-do e capoeira, integrando elementos básicos dessas artes em torno dos princípios da harmonia e da eficiência.
} 
a ser domada, mobilizada e projetada ou irradiada, como um vento de prazer e poder, que só se produz mediante um estado mental de inocência e autenticidade no aqui-agora. Assim, o guerreiro aprende a esvaziar o ego e a experimentar o momento presente através da intuição pura, realizando sua arte com desapego e alegria.

Um dos princípios que aparece como fundamento da pedagogia do guerreiro é o da imitação e repetição de estruturas corporais e mentais, que funcionam como unidades-matrizes das habilidades e dos estados de consciência adequados ao cultivo da arte. Estas unidades básicas se compõem, geralmente, de um ritmo ternário, seja enquanto transformação de tríades mentais, ou de movimentos corporais correspondentes, executados em três tempos. A repetição gera um fluxo de energia que vai realizando um caminho de aprendizagem, permitindo percepções cada vez mais sutis e precisas, apurando os estados de consciência, à medida que se dá a integração dos veículos energéticos corporais. A fixação destas unidades mente-corpo permite a realização de uma gama infinita de possibilidades, criando variações em torno da estrutura triádica profunda. Desta forma, o método da imitação e da repetição nada tem de mecânico e rígido, mas, pelo contrário, aguça a percepção, ativa a sincronização mente-corpo e desenvolve a atenção consciente. A técnica da repetição é utilizada nas artes marciais interiorizadas como forma de aquisição progressiva e lenta de um estado concentrado da mente, no fluir contínuo do movimento fisico, gerando esvaziamento emocional e criação de uma atenção global, que permite a sincronicidade dos fluxos energéticos atuantes no aqui-agora. As metas de aprendizagem (exames, faixas, títulos, graduações) são sempre parciais e apenas sinalizam as etapas que ainda virão, indicando que o processo de construção da atenção consciente é inesgotável e presencial, exigindo a contínua auto-observação e o controle.

A experiência de si mesmo ou auto-observação é exercitada nessas artes através da imagem mental ou símbolos dos caminhos da energia e seus pontos de emissão-recepção, seja no eixo central que une o homem ao céu e à terra (coluna vertebral), seja nos demais fluxos de energia no corpo (meridianos), entre o corpo e o meio-ambiente e entre os corpos, nos exercícios de luta corporal. A regra básica do guerreiro é manter tais caminhos sempre limpos e 
brilhantes e, para tanto, o instrumento é a respiração, entendida não apenas como função pulmonar, mas enquanto monitoração, pela mente, dos variados e sutis sopros vitais e essências que circulam pelo corpo. Esse contato mentecorpo visa à abertura, ao relaxamento dos bloqueios, em todos os veículos corporais, como base para a expressão da espontaneidade e da consciência plena do momento. Várias imagens mentais são utilizadas para mapear o exercício dessa integração corpo-mente, como, por exemplo, as imagens mentais taoístas da circulação do chi, usadas na prática do chi-kun (trabalho com a respiração). Através da tríade fogo-vento-água, o praticante visualiza a energia vital fluindo enquanto essência, a partir dos centros inferiores do corpo (água), transmutándose em vento no centro do peito (o coração reflete o brilho das estrelas) e manifestando o espírito no fogo do olhar interior, soi central que brilha no centro da cabeça. As artes marciais de escola interna também costumam utilizarse das imagens da roda e da espiral para sinalizar a eficácia técnica dos golpes e para gerar a fluidez indispensável dos movimentos, espaço da criatividade. As etapas de aprendizagem aparecem, às vezes, simbolizadas como fases progressivas de performance do círculo, da esfera e da espiral, partindo de um estado de rigidez inicial, até alcançar o centro imóvel em torno do qual gira todo movimento, no homem como no cosmo.

Há, também, as imagens mentais de animais, que, além de ser fruto de uma minuciosa observação e imitação da natureza, atuam pedagogicamente como modos de participação psíquica das qualidades ressaltadas, permitindo a alquimia das emoções e a maestria da criatividade. Nos ensinamentos tibetanos sobre o caminho do guerreiro, encontramos, por exemplo, a imagem do tigre jovem, que representa a simplicidade, o relaxamento, a percepção dos detalhes e a confiança, enquanto o garuda (grande pássaro mítico com tronco humano) representa a mente aberta ao todo, livre do medo, em infinita expansão. Os movimentos do tai-chichuan utilizam-se da imitação de alguns animais (a serpente, a águia, o tigre, o macaco), como codificação de formas básicas de luta, explorando o esquema energético que cada animal representa e suas possíveis correlações na luta, e ligando as imagens a qualidades éticas e espirituais definidas. 
A relação mestre-discípulo nas antigas artes marciais de escola interna é o chão sem o qual nenhum caminho pode ser percorrido. Enquanto expressão de um arquétipo, ela é a descoberta interior e a experiência direta de um sentimento mútuo de união, pois nela ambos, discípulo e mestre, realizam a reciprocidade total que define o verdadeiro amor, a disponibilidade e o acolhimento natural entre os seres, que os orientais chamam de "compaixão". $\mathrm{O}$ mestre, enquanto espelho do eu superior, sinaliza em sua presença interior essencial aquilo que o discípulo deve realizar enquanto guerreiro. Aquele que atua como mestre deve manifestar a experiência interior da união entre o céu e a terra, a qual preside um estado de consciência de abertura e compreensão total do mundo, podendo nele atuar sem medo nem agressão, com sabedoria, sensibilidade e desapego. Enquanto caminho de integração entre o social e o cósmico, a relação mestre-discípulo faz-se acompanhar de regras de conduta ritualizada, que são veículos de modos de ser-estar naturais, compartilhados também entre os discípulos de um mesmo mestre. Por exemplo, na simbologia da reverência, tal como definida no modelo tibetano do guerreiro, o inclinar do corpo numa seqüência de três tempos \{sustentar - ficar de pé frente a frente, inclinar a cabeça - sentir, e curvar todo o corpo entregar) significa para ambos a expressão ritual de uma identidade compartilhada, perante a natureza essencial de todos os seres, como base da hierarquia entre eles existente. Os valores da não-violência e da autodefesa, que caracterizam as artes marciais interiorizadas, decorrem, assim, do próprio cerne das práticas rituais que acompanham seus métodos pedagógicos. Todas as mais variadas formas culturais de expressão do arquétipo do guerreiro (samurai, monge, cavaleiro, capoeira) são sustentadas por sistemas éticos codificados a partir de uma moralidade pura, derivada da vivência de um espaço sagrado e das forças naturais interiorizadas. Em termos de uma ecologia humana, o estado de iluminação espiritual do qual progressivamente se aproximam os discípulos, e que se supõe ser uma conquista plena no mestre, representa um modo de habitar-se e de habitar o mundo, permitindo que a presença do eu superior manifeste seu brilho em todo evento e em toda performance no samsara (mundo das formas). 


\section{Conclusão}

Para voltar à Filosofia, podemos agora compreender melhor de que forma as pedagogias orientais se constróem como caminhos de obtenção de estados de consciência integrados entre o homem e o Universo (cósmico e social), já que elas se baseiam numa cosmovisão totalizante, onde a transdisciplinaridade é um traço essencial, envolvendo num mesmo modelo questões de cunho político, educativo e de conhecimento sistemático do homem e da natureza. A consciência é aí compreendida enquanto fenômeno natural, irradiador da energia que cria as formas, e enquanto tal aparece na filosofia da educação e nas práticas que ela sustenta. A pedagogia das artes marciais interiorizadas mostra com clareza como é possível esta utilização prática da visão metafísica, que representa o mundo ao mesmo tempo enquanto samsara, a roda da vida, no eterno movimento de transmutação das formas pela consciência; e enquanto centro imóvel e luminoso dessa roda, o olho do furacão, o buraco negro por onde se passa instantaneamente ao nirvana, onde quer que você esteja.

O passo seguinte na consecução do projeto de pesquisa sobre Educação Ambiental e Ecologia Humana consiste em discutir as formas pelas quais esses princípios podem ser utilizados em nossa sociedade e em situações de mudança cultural, abordando-se os modos de interconexão com os modelos culturais próprios dos grupos sociais onde estão sendo aplicados, na pesquisa de campo. Este será o tema de um próximo artigo.

\section{Referências bibliográficas}

AMARAL, Sonia. Chi-Kun. respiração taoísta, exercícios para a mente e para o corpo. São Paulo: Summus, 1984.

BRINKER Helmut. O Zen na arte da pintura SãoPaulo: Pensamento, 1987.

BULL, Wagner J. Aikido: o caminho da sabedoria. São Paulo: Pensamento, 1990. 
CHAUBE, S. P. Recent educational philosophies in India. Angra Lucknow: Ram. [19-].

CHATTERJEE, M. Dimensões cósmicas da arte indiana: um estudo preliminar. Reflexão, São Paulo, n.34, jan./abr. 1986.

CHENG, Chao Chang. El deporte terapeutico chino. Madrid. [19-].

CHENG, Wu Jyh. Tai-chi-chuan: a alquimia do movimento. Rio de Janeiro: Objetiva, 1989.

CHIA, Mantak. A energia curativa através do Tao. São Paulo: Pensamento, 1987.

CLIFFORD, Terry. A arte de curar no budismo tibetano. São Paulo: Pensamento, 1987.

DESPEUX, Catherine. Tai-chi-chuan: arte marcial, técnica da longa vida São Paulo: Pensamento, 1987.

GYATSO, Tenzin. Tantrano Tibet. São Paulo: Pensamento, 1988.

HAMMITZSCHE, H. O zen na arte da cerimônia do chá. São Paulo: Pensamento, 1991.

HERRIGEL, Eugen. A arte cavalheiresca do arqueiro zen. São Paulo: Pensamento, [19-].

HUANG, Al Chung-Liang. Expansão e recolhimento: a essência do T'ai Chi. SãoPaulo: Summus, 1979.

HUXLEY, Aldous. A filosofia perene. SãoPaulo: Cultrix, 1991.

HYAMS, Joe. O zen nas artes marciais. São Paulo: Pensamento, 1992. 
JUNG, Carl Gustav. Considerações em torno da psicologia da meditação oriental. In: PSICOLOGIA e religião oriental. Rio de Janeiro: Vozes, 1943-1986.

. A energia psíquica. São Paulo: Vozes, 1928-1987. O espírito na arte e na ciência. Rio de Janeiro: Vozes, 1987. . O eu e o inconsciente. Rio de Janeiro: Vozes, 1928-1987. Memórias: sonhos e reflexões. Rio de Janeiro: Nova Fronteira, 1961-1989.

KABIR, Humayun. Indian philosophy of education. N. Delhi: Asia Publishing House. [19--].

KRISHNAMURTI, J. O verdadeiro objetivo da vida. SãoPaulo: Cultrix, 1986.

KRISTEVA, Julia. Historiada linguagem. Lisboa: Ed. 70, 1983.

MOACANIN, Radmila. A psicologia de Jung e o budismo tibetano. São Paulo: Cultrix, 1989.

NARANJO, Claudio. Psicologia da meditação. São Paulo: Instituto Thame, 1991.

NORMAND, Henry. Os mestres do Tao. São Paulo: Pensamento, 1987.

OLIVEIRA, Roberto Cardoso de. Razão e afetividade: o pensamento de L. Levy-Bruhl. São Paulo: UNICAMP, 1991.

SA, Lais Mourão. Mito, filosofia e ciência: uma abordagem antropológica. In: Enfoque Antropológico e Filosofia. Brasília: Faculdades Integradas da Católica de Brasília, 1994. (Série Filosofia, 5). 
SÁ, Lais Mourão. O psíquico e o simbólico: contribuições para uma teoria junguiana da cultura. Brasília, 1992. Tese (Doutorado)

SING, Chiang. A essência da sabedoria de Confúcio. [S.1.]: Tecnoprint [19--].

SOUZA, Filho, CLÓVIS, C. de. Introdução à psicologia tibetana. Rio de Janeiro: Vozes, 1983.

SOUZENELLE, Annick de. O simbolismo do corpo humano: da árvore da vida ao esquema corporal. São Paulo: Pensamento, 1988.

TAIMNI, I. K. Autocultura à luz do ocultismo. Rio de Janeiro: Sociedade Teosòfica no Brasil, 1980.

TAIMNI, I. K. O homem, Deus e o universo. SãoPaulo: Pensamento, 1989.

TIBERY, Antonio. AMI-Jitsu: o caminho da integração. Brasília: Thesaurus, 1993.

TRUNGPA, Chógyan. Shambala. a trilha sagrada do guerreiro. São Paulo: Cultrix, 1992.

TULKU, Tarthang. A expansão da mente. São Paulo: Cultrix, 1988. Gestos de equilíbrio. SãoPaulo: Pensamento, 1989.

UNGER, Nancy Mangabeira. O encantamento do humano, ecologia e espiritualidade. SãoPaulo: Loyola, 1991.

VILLADORATA, M. N. Aikido. Rio de Janeiro: Record, 1973.

ZIMMER, Heinrich. Filosofias da índia. [S.1.]: Palas Athena, 1986. 
Lais Mourão de Sá, doutora em Antropologia Social pela Universidade de Brasília (UnB), é professora do Departamento de Teoria e Fundamentos da Faculdade de Educação da referida universidade.

This is a psycho-anthropological approach of the pedagogic patterns engendered in the cultural context of the ancient orient. It is based upon intercultural comparison andjunguian theory of culture. The aim is Io offer a theoretical reference for the understanding and interpretation of human 's ancient pedagogic conceptions. It is also supposed that this ethnographic support can help the researches in the field of new methodologies for Ambiental Education and Human Ecology. In the text are presented and described some practical and theoretical categories that support education philosophy in these ancient models, such as: the concept of tradition, the notion of practical philosophy, that of inner alchemy, aesthetic experience, the ethical approach of ecology, and the pedagogy of inner martial arts. The conclusions point out to a further step consisting in the reflection about the needed mediations to the construction of new pedagogies for cultural change, inspired on these ancient patterns, in this critical moment of contemporary society. The field work is part of an action-research enterprise, in which it is tested the efficacy of the models studied, while developping formative processes of people involved in the experience. So it is furthered a practical reflections about human ecology and cultural change.

Ils 'agit d'une approche psycho-anthropologique sur les modeles pédagogiques engendres dans le contexte culturel de l'ancien orient, basée dans une étude comparative interculturelle et dans la théorie junguienne de la culture. Le but de cette étude est de créer un point de référence théorique qui puisse servir à la compréhension et à l'interprétation des 
conceptions pédagogiques anciennes de l'humanité. A partir de cette base ethnographique il sera peut-être possible de soulever quelques principes méthodologiques pour l'Education Ambientale et l'Ecologie Humaine. Ici on approche les catégories pratiques et théoriques qui sont le fondement de la philosophie de l 'éducation dans ces modèles de la culture orientale ancienne. On se détient sur le concept de tradition, la notion de philosophie pratique, celle d'alchimie intérieure, expérience esthétique, l 'éthique de l'écologie et la pédagogie des arts martiaux d'école interne. Les conclusions présentent des réflexions qui portent à une nouvelle étape qui consistera dans la discussion sur les médiations nécessaires pour établir des pédagogies tournées vers le changement culturel, dam un moment de crise telle que subit la société contemporaine. Cette entreprise fait partie d'un projet de recherche-action où il est mis en pratique les principes pédagogiques étudiés et mesurée son efficacité. $L$ 'experience permet aussi de développer des processus formatifs des personnes qu 'y participent. Cela peut promouvoir une réflexion pratique sur l'écologie humaine et le changement culturel.

Éste es un enfoque psico-antropologi co de los modelos pedagógicos engendrados en el contexto cultural del antiguo oriente. Fundamentase en la comparación intercultural y en la teoría junguiana de la cultura. El objetivo es de criar una referencia teórica para la comprensión y interpretación de las concepciones pedagógicas ancestrales de la humanidad. Se supone además que esta base etnográfica sea de utilidad en las investigaciones acerca de nuevas metodologías para Educación A m bien tal y Ecología Humana. En el texto se presentan y se describen las siguientes categorías práctico-teóricas que fundamentan la filosofía de la educación en estos ancianos modelosculturales: el concepto de tradición, la noción de filosofía práctica, de alquimia interior, la experiencia estética, el enfoque ético de la ecología y la pedagogia de las artes marciales. Las conclusiones apuntan hacia 
una reflexión subsecuente acerca de las mediaciones necesarias para que estos modelos puedan inspirar la construcción de nuevas pedagogías para el cambio cultural, en este momento crítico de la sociedad contemporánea. El trabajo de campo esparte de una empresa de pesquisaacción en la cual se hace prueba de la eficacia de los principios pedagógicos estudiados, mientras que se desarrollan procesos formativos de las personas envolvidas en la experiencia. De este modo se desarrolla una reflexión práctica acerca de ecologia humana y cambio cultural. 